\title{
ANALISIS PERMINTAAN KOPI ARABIKA ROASTING DI KECAMATAN BANDAR KABUATEN BENER MERIAH
}

(Demand Analysis Of Arabica Coffee Roasting In Kecamatan Bandar

Kabupaten Bener Meriah)

\author{
Rauzatul Jannah ${ }^{1}$, Sofyan $^{1}$, Akhmad Baihaqi ${ }^{*}$ \\ ${ }^{1}$ Program Studi Agribisnis, Fakultas Pertanian, Universitas Syiah Kuala
}

\begin{abstract}
Abstrak - Kopi arabika (Arabica coffe L) merupakan minuman yang digemari oleh masyarakat di seluruh dunia yang sudah menjadi bagian dari kehidupan manusia sehari-hari. Permintaan kopi arabika Indonesia terus meningkat setiap tahun, kopi arabika yang dihasilkan oleh berbagai daerah di Indonesia mempunyai karakteristik dan cita rasa yang unik. Penelitian ini bertujuan untuk mengetahui pengaruh faktor harga kopi arabika roasting (specialty, premium, longberry), harga greenbean arabika (specialty, premium, longberry), harga kopi robusta dan promosi terhadap permintaan kopi arabika roasting (sangrai) dengan menggunakan persamaan Regresi Linier Berganda. Sampel dalam penelitian ini adalah pengusaha pengolahan kopi arabika roasting yang berada di Kecamatan Bandar Kabupaten Bener Meriah. Pengumpulan data diperoleh dari data primer dan data sekunder. Hasil penelitian menunjukkan bahwa masing-masing hipotesis 1, 2 dan 3 yang berpengaruh nyata terhadap permintaan kopi arabika roasting adalah $\left(\mathrm{X}_{2}\right)$ yaitu harga greenbean arabika specialty $\left(\mathrm{X}_{2 \mathrm{a}}\right)$, harga greenbean arabika premium $\left(\mathrm{X}_{2 \mathrm{~b}}\right)$ dan harga greenbean arabika longberry $\left(\mathrm{X}_{2 \mathrm{c}}\right)$

Kata kunci : Kopi Arabika, Roasting, Harga, premium, specialty, premium, longberry.
\end{abstract}

\begin{abstract}
Arabica coffee (Arabica coffe L) is beverage favored by people around the world who have become part of everyday human life. Indonesian Arabica coffee demand continues to increase every year, Arabica coffee produced by the various regions in Indonesia has the characteristics and unique taste. This research aims to knowing influence factors of arabica roasting coffee prices (specialty, premium, longberry), arabica greenbean prices (specialty, premium, longberry), robusta coffee prices and promotion on demand for arabica roasting by using multiple linear regression equation The sample of research was the businessman of arabica coffee roasting in Kecamatan Bandar Kabupaten Bener Meriah. Collection of data obtained from the primary and secondary data. The results showed that each of these hypotheses 1, 2 and 3 which significantly affected the demand for arabica coffee roasting is (X2) which is arabica specialty greenbean prices (X2a), arabica premium greenbean prices (X2b) and arabica longberry greenbean prices (X2c).
\end{abstract}

Keywords: Arabica coffee, roasting, prices, specialty, premium, longberry.

\section{PENDAHULUAN}

Kopi arabika (Arabica coffe L) merupakan minuman yang digemari oleh bangsa-bangsa di seluruh dunia yang sudah menjadi bagian dari kehidupan manusia sehari-hari. Minuman ini diperlukan untuk menopang berbagai kegiatan bangsa-bangsa selain memberikan rasa lezat khas kopi. Saat ini kopi arabika merupakan salah satu bahan perdagangan penting dunia dan melibatkan jaringan perdagangan antar bangsa dari Negara-negara berkembang ke Negaranegara maju yang merupakan konsumen utama (Siswoputranto, 1993).

Salah satu daerah penghasil utama kopi arabika di Indonesia adalah Provinsi Aceh, Sumatera Selatan, Bengkulu, Sumatera Utara dan Sumatera Barat. Di Aceh tanaman kopi 
arabika diusahakan dengan pola perkebunan rakyat. Pola perkebunan rakyat merupakan pola pengusaha kopi yang terbesar. Pusat penghasil tanaman kopi di Provinsi Aceh terdapat di Kabupaten Aceh Tengah dan Kabupaten bener Meriah. Kedua daerah ini menjadikan kopi sebagai prioritas utama dalam peningkatan produksi dan kualitas untuk perencanaan pembangunan perkebunan ke masa yang akan datang (Fahmi, 2013). Menurut Badan Pusat Statistik Aceh (2014), produksi kopi di Kabupaten Aceh Tengah 27.079 ton dengan luas tanam 48.300 ha. Kabupaten Bener Meriah produksi kopi arabika sebesar 15.000 ton dengan luas tanam 39.496 ha.

Pada tahun 2012 terjadi modernisasi meminum kopi, bermunculan café dan usaha roasting. Tumbuhnya kopi shop atau kopi retail yang saat ini sudah berjamur dan berjumlah sedikitnya 12 kedai atau toko dengan merek kopi arabika Gayo yang meyakinkan kita bahwa kopi arabika Gayo memang sedang tumbuh dan bermetamorfosis menuju kopi arabika Gayo yang lebih mantap. Disini terjadi perubahan tentang cara menikmati kopi dimana kopi arabika mulai dilirik sebagai kopi yang juga dinikmati, tidak sekedar sebuah komoditas ekspor (Nurazizi, 2013).

Terdapat banyak jenis olahan kopi arabika yang dihasilkan oleh industri pengolahan kopi di Kecamatan Bandar Kabupaten Bener Meriah, diantaranya yaitu kopi arabika roasting specialty, kopi arabika roasting premium dan kopi arabika roasting longberry. Ketiganya dibuat melalui prosesing yang berbeda dengan harga yang berbeda. Sehingga masing-masing memiliki nilai tambah yang berbeda. Sebagai gambaran harga yang diterima petani apabila bila menjual hasil dalam bentuk greenbean arabika (tanpa olahan) yaitu harga greenbean arabika specialty sebesar Rp. 102.500 / Kg, harga greenbean arabika premium sebesar Rp. 72.500 / Kg dan harga greenbean arabika longberry sebesar Rp. 130.000 / Kg. Kemudian harga untuk Kopi arabika roasting specialty sebesar Rp. 160.000 / Kg, harga kopi arabika roasting premium sebesar Rp. 132.500 / Kg dan harga kopi arabika roasting longberry sebesar Rp. 205.000 / Kg. Sehingga harga jual kopi olahan lebih menguntungkan, namun sampai dengan saat ini petani belum banyak mengembangkan produk olahan ini. Hal ini dikarenakan umumnya petani belum mengetahui manfaat produk olahan kopi arabika bagi peningkatan pendapatan.

Semakin berkembangnya usaha roasting arabika mengakibatkan banyaknya pilihan konsumen antara dan konsumen akhir untuk memilih sesuai dengan selera mereka. Maka peneliti tertarik untuk mengetahui faktor apa saja yang mempengaruhi permintaan kopi arabika roasting di Kecamatan Bandar Kabupaten Bener Meriah.

Tujuan yang ingin dicapai dalam penelitian ini adalah : 1. Mengetahui pengaruh harga kopi arabika roasting specialty, harga greenben arabika specialty, harga kopi robusta dan promosi terhadap permintaan kopi arabika roasting (Sangrai) di Kecamatan Bandar Kabupaten Bener Meriah. 2. Mengetahui pengaruh harga kopi arabika roasting premium, harga greenben arabika premium, harga kopi robusta dan promosi terhadap permintaan kopi arabika roasting (Sangrai) di Kecamatan Bandar Kabupaten Bener Meriah. 3. Mengetahui pengaruh harga kopi arabika roasting longberry, harga greenben arabika longberry, harga kopi robusta dan promosi terhadap permintaan kopi arabika roasting (Sangrai) di Kecamatan Bandar Kabupaten Bener Meriah.

\section{METODOLOGI PENELITIAN}

Lokasi penelitian ini dilakukan di Desa Pondok Baru Kecamatan Bandar Kabupaten Bener Meriah. Penentuan lokasi penelitian dilakukan dengan sengaja (Purposive sampling) dengan alasan pemilihan lokasi penelitian didasarkan atas pertimbangan bahwa Desa Pondok Baru Kecamatan Bandar merupakan salah satu daerah usaha roasting kopi. Objek penelitian 
ini adalah pengusaha pengolahan kopi arabika roasting pada Desa Pondok Baru Kecamatan Bandar Kabupaten Bener Meriah. Ruang lingkup penelitian ini adalah terbatas pada keadaan permintaan kopi arabika roasting di Desa Pondok Baru Kecamatan Bandar Kabupaten Bener Meriah.

Metode analisis yang digunakan dalam penelitian ini adalah regresi linear berganda. Analisis regresi berganda adalah pengembangan dari analisis regresi sederhana. Kegunaanya yaitu untuk meramalkan nilai variabel terikat (Y) apabila variabel bebas minimal dua atau lebih (Riduan dan Akdon,2009). Sehingga model persamaannya sebagai berikut :

$$
Y=a X_{1}{ }^{a 1} X_{2}{ }^{a 2} \ldots X n^{a n} \mathrm{e}^{\mu}
$$

Maka model ini dapat ditransformasikan ke dalam bentuk linear berganda dengan cara melogaritmakan persamaan tersebut menjadi :

$$
\begin{aligned}
& \log Y=\log a+a 1 \log X 1+a 2 \log X 2+a 3 \log X 3+a 4 \log X 4+\mu \\
& Y=a 0+a 1 X 1+a 2 X 2+a 3 X 3+a 4 X 4+\mu
\end{aligned}
$$

1. Hipotesis Pertama

$\log \mathrm{Y}=\log \mathrm{a}+\mathrm{a} 1 \log \mathrm{X} 1+\mathrm{a} 2 \log \mathrm{X} 2+\mathrm{a} 3 \log \mathrm{X} 3+\mathrm{a} 4 \log \mathrm{X} 4+\mu$

$\mathrm{Y}=\mathrm{a} 0+\mathrm{a} 1 \mathrm{X} 1+\mathrm{a} 2 \mathrm{X} 2+\mathrm{a} 3 \mathrm{X} 3+\mathrm{a} 4 \mathrm{X} 4+\mu$

Dimana :

Y

$\mathrm{X} 1 \mathrm{a}$

$\mathrm{X} 2 \mathrm{a}$

$\mathrm{X} 3$

$\mathrm{X} 4$

$\mathrm{a} 0$

$\mathrm{a} 1, \mathrm{a} 2, \mathrm{a} 3$,

$\mu$

2. Hipotesis Kedua

Dimana :

Y

$\mathrm{X} 1 \mathrm{~b}$

$\mathrm{X} 2 \mathrm{~b}$

$\mathrm{X} 3$

$\mathrm{X} 4$

$\mathrm{a} 0$

$\mathrm{a} 1, \mathrm{a} 2, \mathrm{a} 3$,

$\mu$

3. Hipotesis Ketiga

Dimana :

Y

$\mathrm{X} 1 \mathrm{c}$

$\mathrm{X} 2 \mathrm{c}$

$\mathrm{X} 3$

$\mathrm{X} 4$

$\mathrm{a} 0$
$=$ Permintaan kopi arabika roasting $(\mathrm{Rp} / \mathrm{kg} / \mathrm{bln})$

= Harga kopi arabika roasting specialty $(\mathrm{Rp} / \mathrm{bln})$

$=$ Harga greanbean kopi arabika specialty $(\mathrm{Rp} / \mathrm{bln})$

= Harga kopi robusta $(\mathrm{Rp} / \mathrm{bln})$

$=$ Promosi (usaha/kegiatan)

= Konstanta

$=$ Koefisien regresi

$=$ Error term

$\log \mathrm{Y}=\log \mathrm{a}+\mathrm{a} 1 \log \mathrm{X} 1+\mathrm{a} 2 \log \mathrm{X} 2+\mathrm{a} 3 \log \mathrm{X} 3+\mathrm{a} 4 \log \mathrm{X} 4+\mu$

$\mathrm{Y}=\mathrm{a} 0+\mathrm{a} 1 \mathrm{X} 1+\mathrm{a} 2 \mathrm{X} 2+\mathrm{a} 3 \mathrm{X} 3+\mathrm{a} 4 \mathrm{X} 4+\mu$

$=$ Permintaan kopi arabika roasting $(\mathrm{Rp} / \mathrm{kg} / \mathrm{bln})$

$=$ Harga kopi arabika roasting premium $(\mathrm{Rp} / \mathrm{bln})$

$=$ Harga greenbean kopi arabika premium $(\mathrm{Rp} / \mathrm{bln})$

$=$ Harga kopi robusta $(\mathrm{Rp} / \mathrm{bln})$

$=$ Promosi (usaha/kegiatan)

$=$ Konstanta

$=$ Koefisien regresi

$=$ Error term

$\log \mathrm{Y}=\log \mathrm{a}+\mathrm{a} 1 \log \mathrm{X} 1+\mathrm{a} 2 \log \mathrm{X} 2+\mathrm{a} 3 \log \mathrm{X} 3+\mathrm{a} 4 \log \mathrm{X} 4+\mu$

$Y=a 0+a 1 X 1+a 2 X 2+a 3 X 3+a 4 X 4+\mu$

$=$ Permintaan kopi arabika roasting $(\mathrm{Rp} / \mathrm{kg} / \mathrm{bln})$

= Harga kopi arabika roasting longberry $(\mathrm{Rp} / \mathrm{bln})$

= Harga greanbean kopi arabika longeberry $(\mathrm{Rp} / \mathrm{bln})$

= Harga kopi robusta $(\mathrm{Rp} / \mathrm{bln})$

$=$ Promosi (usaha/kegiatan)

$=$ Konstanta 


$$
\begin{array}{ll}
\mathrm{a} 1, \mathrm{a} 2, \mathrm{a} 3, & =\text { Koefisien regresi } \\
\mu & =\text { Error term }
\end{array}
$$

\section{Uji Penyimpanan Asumsi Klasik}

Model regresi linear dapat disebut sebagai model yang baik jika model tersebut memenuhi beberapa asumsi yang kemudian disebut dengan asumsi klasik. Untuk memenuhi asumsi tersebut maka peneliti akan menggunakan uji multikolinearitas, uji heterokedastisitas, dan uji normalitas.

Multikolinearitas

Metode perhitungan ini digunakan untuk menghitung apakah ada korelasi antar variabel independen. Jika terjadi korelasi, maka dikatakan terdapat multikolinearitas (Singgih Santoso, 1999).

\section{Heteroskedastisitas}

Metode ini digunakan untuk menguji apakah dalam model regresi linear kesalahan pengganggu mempunyai varian yang sama atau tidak dari satu pengamatan ke pengamatan yang lain. Salah satu cara untuk mendeteksi ada atau tidaknya heteroskedastisitas dengan melihat grafik plot antara nilai prediksi variabel terikat (dependen). Deteksi ada atau tidaknya heteroskedastisitas dapat dilakukan dengan melihat ada atau tidaknya pola tertentu pada grafik scatterplot, dimana sumbu Y adalah Y yang telah diprediksi dan sumbu X adalah residual yang telah di-studentized. Ghozali (2009.

\section{Normalitas}

Uji normalitas bertujuan untuk menguji apakah nilai residual yang telah distandardisasi pada model regresi berdistribusi normal atau tidak. Uji normalitas yang digunakan dalam penelitian ini adalah uji Kolmogorov-Smirnov dengan menggunakan fungsi distribusi kumulatif. Nilai residual terstandardisasi berdistribusi normal jika sig. > alpha. Jika hasil Assym. Sig. (2-tailed) >0,05 maka data beristribusi normal dan jika Asymp. Sig. (2-tailed) < 0,05 maka data berdistribusi tidak normal.

\section{Pengujian Hipotesis}

Uji t

Uji t digunakan untuk menunjukkan apakah masing-masing variabel independen berpengaruh terhadap variabel dependent. Sedangkan kriteria pengujian adalah sebagai berikut :

$$
t_{\operatorname{cami} i}=\frac{a i}{S E_{a i}}
$$

Keterangan:

$\mathrm{Ai} \quad=$ Koefisien regresi

SEai $\quad=$ Standar Eror

Dengan ketentuan:

$\mathrm{t}($ cari $)=>\mathrm{t}($ tabel $)$, pada taraf nyata 0,05 maka terima Ha dan tolak $\mathrm{H} 0$, artinya variabelvariabel bebas mempunyai pengaruh yang nyata (significant) terhadap variabel terikat.

$\mathrm{t}($ cari $)=<\mathrm{t}($ tabel $)$, pada taraf nyata 0,05 maka terima $\mathrm{H} 0$ dan tolak Ha, , artinya variabelvariabel bebas tidak berpengaruh nyata (non significant) terhadap variabel terikat. 


\section{Uji Validasi Model (F)}

Untuk mengetahui peranan variabel yang mempengaruhi terhadap variabel yang dipengaruhi secara serempak (bersama-sama) digunakan uji " $F$ " dengan menggunakan rumus (sudjana, 2005) sebagai berikut :

$$
F_{(\text {hitung) }}=\frac{R^{2} / k}{\left(1-R^{2}\right)(n-k-1)}
$$

Keterangan:

$\mathrm{R} 2=$ Koefisien determinasi

$\mathrm{K} \quad$ = Banyaknya variabel bebas

$\mathrm{n} \quad=$ Jumlah sampel

Dimana:

FCari $=>$ FTabel, pada taraf nyata 0,05 maka terima Ha dan tolak H0, artinya variabelvariabel bebas mempunyai pengaruh nyata (significant) terhadap variabel terikat.

FCari $=$ <FTabel, pada taraf nyata 0,05 maka terima $\mathrm{H} 0$ dan tolak Ha, artinya variabelvariabel bebas tidak berpengaruh nyata (non significant) terhadap variabel terikat.

\section{Pengujian Ketepatan (R2)}

Untuk melihat hubungan antara variabel bebas (x1, x2, x3 dan $\mathrm{x} 4)$ dengan variabel terikat $(\mathrm{Y})$ dianalisis dengan koefisien determinasi (R2), yaitu sebagai berikut:

$$
\mathrm{R}^{2}=\frac{\not K r g g}{\Sigma Y}
$$

Dimana:

$\mathrm{R} 2=$ koefisien determinasi antara $\mathrm{x} 1, \mathrm{x} 2, \mathrm{x}$ 3dan $\mathrm{x} 4$ sebagai variabel bebas $(\mathrm{X})$ terhadap variabel terikat $(\mathrm{Y})$

$\mathrm{Jk}(\mathrm{Reg})=$ Jumlah kuadrat untuk regresi

$\sum \mathrm{Y}=$ Jumlah total permintaan kopi arabika roasting

\section{Skala Pengukuran}

Dalam penelitian ini, skala pengukuran yang digunakan untuk variabel promosi adalah skala likert. Menurut Kriyantono (2006), skala likert merupakan skala yang digunakan untuk mengukur sikap, pendapat, dan persepsi seseorang atau kelompok orang tentang kejadian atau gejala sosial (Sugiyono, 2010).

Cara pengukuran adalah dengan menghadapkan seorang responden dengan sebuah pernyataan dan kemudian dimana untuk memberikan jawaban dari lima pilihan jawaban, dimana masing-masing jawaban memiliki nilai yang berbeda.

Dalam penelitian ini digunakan pertanyaan dengan rentang skala penilaian yaitu :

STB : Sangat Tidak Baik : 1

TB : Tidak Baik : 2

CB : Cukup Baik $\quad: 3$

B : Baik : : 4

SB : Sangat Baik $\quad: 5$ 


\section{HASIL DAN PEMBAHASAN}

Faktor-Faktor Yang Mempengaruhi Permintaan Kopi Arabika Roasting

\section{Harga Kopi Arabika Roasting}

Harga kopi arabika roasting merupakan nilai harga produk di kali dengan jumlah permintaan konsumen terhadap kopi arabika roasting. Adapun harga yang di peroleh kopi arabika roasting (specialty, premium, longberry) dapat dilihat pada Tabel 1.

Tabel 1. Harga Kopi Arabika Roasting (Specialty, Premium, Longberry) Bulan April 2015 Juni 2016.

\begin{tabular}{|l|r|r|r|}
\hline \multicolumn{1}{|c|}{ Bulan } & $\begin{array}{c}\text { Kopi Arabika } \\
\text { Specialty (Rp) }\end{array}$ & $\begin{array}{c}\text { Kopi Arabika } \\
\text { Premium (Rp) }\end{array}$ & $\begin{array}{c}\text { Kopi Arabika } \\
\text { Longberry (Rp) }\end{array}$ \\
\hline April & 19.840 .000 & 5.300 .000 & 2.870 .000 \\
\hline Mei & 22.400 .000 & 2.517 .500 & 1.100 .000 \\
\hline Juni & 18.560 .000 & 2.915 .000 & 1.435 .000 \\
\hline July & 18.240 .000 & 3.047 .500 & 1.435 .000 \\
\hline Agustus & 29.920 .000 & 3.710 .000 & 3.690 .000 \\
\hline September & 32.800 .000 & 4.240 .000 & 2.050 .000 \\
\hline Oktober & 35.360 .000 & 3.047 .500 & 3.075 .000 \\
\hline November & 30.080 .000 & 3.180 .000 & 2.870 .000 \\
\hline Desember & 32.320 .000 & 4.372 .500 & 2.255 .000 \\
\hline Januari & 29.120 .000 & 4.240 .000 & 2.255 .000 \\
\hline Februari & 39.200 .000 & 4.637 .500 & 1.640 .000 \\
\hline Maret & 35.200 .000 & 5.035 .000 & 3.485 .000 \\
\hline April & 35.520 .000 & 3.975 .000 & 2.460 .000 \\
\hline Mei & 32.160 .000 & 6.360 .000 & 3.075 .000 \\
\hline Juni & 36.320 .000 & 3.975 .000 & \\
\hline Sumber & & & \\
\hline
\end{tabular}

Sumber : Data Primer, 2016

Berdasarkan Tabel 1, terdapat perbedaan harga kopi arabika roasting specialty, premium dan longberry. Harga kopi arabika roasting specialty lebih tinggi dibandingkan dengan harga kopi arabika roasting premium dan longberry yaitu sebesar $\mathrm{Rp}$. 39.200.000. artinya bahwa permintaan konsumen terhadap kopi arabika roasting specialty lebih tinggi dibandingkan dengan dua jenis kopi arabika roasting lainnya. Hal ini dikarenakan kualitas kopi arabika roasting specialty yang lebih bagus.

\section{Harga GreenBean Arabika}

Harga greenbean arabika merupakan harga produk di kali dengan jumlah permintaan konsumen terhadap greenbean arabika. Adapun harga yang di peroleh hargagreenbean arabika (specialty, premium, longberry) dapat dilihat pada Tabel 2. 
Tabel 2. HargaGreenBean Arabika (Specialty, Premium, Longberry) Bulan April 2015 - Juni 2016

\begin{tabular}{|l|r|r|r|}
\hline \multicolumn{1}{|c|}{ Bulan } & $\begin{array}{c}\text { GreenBean Arabika } \\
\text { Specialty (Rp) }\end{array}$ & $\begin{array}{c}\text { GreenBean Arabika } \\
\text { Premium (Rp) }\end{array}$ & $\begin{array}{c}\text { GreenBean } \\
\text { Arabika Longberry } \\
\text { (Rp) }\end{array}$ \\
\hline April & 12.710 .000 & 2.900 .000 & 1.820 .000 \\
\hline Mei & 14.350 .000 & 1.377 .500 & 2.600 .000 \\
\hline Juni & 11.890 .000 & 1.595 .000 & 1.170 .000 \\
\hline July & 11.685 .000 & 1.667 .500 & 910.000 \\
\hline Agustus & 19.167 .500 & 2.030 .000 & 910.000 \\
\hline September & 21.012 .500 & 2.320 .000 & 1.340 .000 \\
\hline Oktober & 22.652 .500 & 1.667 .500 & 1.950 .000 \\
\hline November & 19.270 .000 & 1.740 .000 & 1.820 .000 \\
\hline Desember & 20.705 .000 & 2.392 .500 & 1.430 .000 \\
\hline Januari & 18.655 .000 & 2.537 .500 & 1.430 .000 \\
\hline Februari & 25.112 .500 & 2.755 .000 & 1.040 .000 \\
\hline Maret & 22.550 .000 & 2.175 .000 & 2.210 .000 \\
\hline April & 22.755 .000 & 2.175 .000 & 1.560 .000 \\
\hline Mei & 20.602 .500 & 3.480 .000 & 1.950 .000 \\
\hline Juni & 23.267 .500 & 2.175 .000 & \\
\hline
\end{tabular}

Sumber : Data Primer, 2016

Berdasarkan Tabel 2 diatas, bahwa harga greenbean arabika specialty lebih tinggi dibandingkan harga greenbean arabika premium dan greenbean arabika longberry yaitu sebesar Rp. 25.112.500. Sama halnya dengan kopi arabika roasting specialty, greenbeen arabika specialty memiliki kualitas yang bagus.

\section{Harga Kopi Robusta}

Harga kopi robusta merupakan nilai harga produk di kali dengan jumlah permintaan konsumen terhadap kopi robusta. Adapun harga yang di peroleh harga kopi robusta dapat dilihat pada Tabel 3.

Tabel 3. HargaKopi Robusta Bulan April 2015 - Juni 2016

\begin{tabular}{|r|l|r|}
\hline No. & \multicolumn{1}{|c|}{ Bulan } & \multicolumn{1}{|c|}{ HargaKopi Robusta (Rp) } \\
\hline 1 & April & 1.600 .000 \\
\hline 2 & Mei & 720.000 \\
\hline 3 & Juni & 720.000 \\
\hline 4 & July & 1.280 .000 \\
\hline 5 & Agustus & 1.440 .000 \\
\hline 6 & September & 1.600 .000 \\
\hline 7 & Oktober & 1.760 .000 \\
\hline 8 & November & 2.160 .000 \\
\hline 9 & Desember & 2.720 .000 \\
\hline 10 & Januari & 3.200 .000 \\
\hline 11 & Februari & 1.520 .000 \\
\hline 12 & Maret & 2.880 .000 \\
\hline 13 & April & 2.640 .000 \\
\hline 14 & Mei & 2.080 .000 \\
\hline 15 & Juni & 2.800 .000 \\
\hline
\end{tabular}

Sumber : Data Primer, 2016

Analisis Permintaan Kopi Arabika Roasting di Kecamatan Bandar Kabupaten Bener Meriah 328 (Rauzatul Jannah, Sofyan ,Akhmad Baihaqi)

Jurnal Ilmiah Mahasiswa Pertanian Unsyiah, Vol. 2, No. 2, Mei 2017: 322-334 
Berdasarkan Tabel diatas menunjukkan bahwa terjadinya perbedaan harga kopi robusta pada setiap bulannya. Adapun harga tertinggi terjadi pada bulan Januari yaitu sebesar Rp. 3.200.000. Hal ini juga menunjukkan bahwa harga kopi robusta lebih rendah dibandingkan dengan harga kopi arabika.

\section{Promosi}

Selain harga kopi arabika roasting (specialty, premium, longberry), harga greenbean arabika (specialty, premium, longberry) dan harga kopi robusta, promosi juga merupakan salah satu faktor yang mempengaruhi permintaan kopi arabika roasting. Hasil dari penelitian menunjukkan bahwa promosi yang dilakukan oleh pengusaha masih kurang dikarenakan kurangnya pengetahuan pengusaha dalam teknologi seperti dalam memanfaatkan teknologi sebagai media dalam mempromosikan kopi arabika roasting seperti melalui internet dan periklanan. Menurut hasil wawancara peneliti dengan pengusaha kopi arabika roasting, manyoritas masyarakat mengetahui produk kopi arabika roasting ini melalui informasi dari telemarketing.

\section{Analisis Faktor Yang Berpengaruh Terhadap Permintaan Kopi Arabika Roasting di Kecamatan Bandar Kabupaten Bener Meriah}

Setelah mengadakan penelitian permintaan kopi arabika roasting di Kecamatan Bandar Kabupaten Bener Meriah, faktor-faktor yang mempegaruhi peningkatan permintaan yang diteliti dalam penelitian ini adalah harga (specialty, premium, longberry), harga greenbean arabika (specialty, premium, longberry), kopi robusta dan promosi. Besarnya pengaruh faktorfaktor permintaan terhadap kopi arabika roasting di analisis dengan menggunakan metode analisis linear berganda dengan menggunakan SPSS . Peningkatan permintaan kopi arabika roasting mempunyai hubungan dengan faktor harga kopi arabika (specialty, premium, longberry), harga greenbean arabika (specialty, premium, longberry), kopi robusta dan promosi. Untuk mengetahui besarnya pengaruh faktor tersebut terhadap permintaan kopi arabika roasting, maka dapat dilihat pada pembahasan dibawah ini.

\section{Pengujian Hipotesis I}

Besarnya pengaruh permintaan kopi arabika roasting di Kecamatan Bandar Kabupaten Bener Meriah dapat dicari dengan pengujian analisis regresi linear berganda dengan pengelompokan data dalam 4 (empat) variabel independen yaitu harga kopi arabika roasting specialty $\left(\mathrm{X}_{1 \mathrm{a}}\right)$, harga greenbean arabika specialty $\left(\mathrm{X}_{2 \mathrm{a}}\right)$, harga kopi robusta $\left(\mathrm{X}_{3}\right)$ dan promosi $\left(\mathrm{X}_{4}\right)$. Dan variabel permintaan kopi arabika roasting sebagai variabel dependen (Y). Pada hipotesis 1 ini yang mempengaruhi permintaan kopi arabika roasting adalah harga greenbean arabika specialty $\left(\mathrm{X}_{2 \mathrm{a}}\right)$. Sedangkan variabel yang lain tidak berpengaruh nyata terhadap kopi arabika roasting. Hasil estimasi koefisien regresi yang diperoleh dapat dilihat pada Tabel 4.

Tabel 4. Hasil Analisis Regresi Linear Hipotesis 1

\begin{tabular}{|c|c|c|c|c|c|c|c|}
\hline \multirow{2}{*}{ Model } & \multicolumn{2}{|c|}{$\begin{array}{c}\text { Unstandardized } \\
\text { Coefficients }\end{array}$} & \multirow{2}{*}{$\begin{array}{c}\begin{array}{c}\text { Standardized } \\
\text { Coefficients }\end{array} \\
\text { Beta }\end{array}$} & \multirow{2}{*}{$\mathrm{T}$} & \multirow{2}{*}{ Sig. } & \multicolumn{2}{|c|}{$\begin{array}{c}\text { Collinearity } \\
\text { Statistics }\end{array}$} \\
\hline & B & $\begin{array}{l}\text { Std. } \\
\text { Error }\end{array}$ & & & & $\begin{array}{c}\text { Toleranc } \\
\mathrm{e}\end{array}$ & VIF \\
\hline (Constant) & $-8,140$ & ,982 & & $-8,290$ & ,000 & & \\
\hline $\mathrm{X} 1 \mathrm{a}$ &,- 042 & , 102 &,- 048 &,- 411 & ,690 & ,294 & 3,402 \\
\hline $\mathrm{X} 2 \mathrm{a}$ & ,853 & , 120 & 1,020 & 7,081 &, 000 & ,191 & 5,242 \\
\hline $\mathrm{X} 3$ & ,006 & ,042 & ,014 &, 150 & ,884 & ,486 & 2,059 \\
\hline $\mathrm{X} 4$ & ,040 & ,022 & ,119 & 1,843 & ,095 & ,946 & 1,057 \\
\hline
\end{tabular}

Sumber : Data Primer (di olah), 2016

Analisis Permintaan Kopi Arabika Roasting di Kecamatan Bandar Kabupaten Bener Meriah 329 
Pada Tabel 4 diatas dapat diambil persamaan regresi linier berganda sebagai berikut:

$$
Y=-8,140-0,042 X_{1 a}+0,853 X_{2 a}+0,006 X_{3}+0,040 X_{4}
$$

\section{Harga Kopi Arabika Roasting Specialty $\left(\mathbf{X}_{1 \mathrm{a}}\right)$}

Berdasarkan hasil analisis regresi linear Tabel 9 dapat dijelaskan yaitu Setiap peningkatan Rp.1,-/Kg harga kopi arabika roasting specialty akan menurunkan jumlah permintaan kopi arabika roasting sebesar $0,042 \mathrm{Kg}$ dengan asumsi variabel lain tetap. Dan berdasarkan hasil uji-t statistik, hasil analisis harga kopi arabika roasting specialty yang didapatkan thitung sebesar 0,411 dengan tingkat signifikansi sebesar 0,690, maka nilai $t_{\text {hitung }} 0,411<\mathrm{t}_{\text {tabel }} 2,570$ dengan tingkat kepercayaan 95\% dan tingkat signifikansi $0,05(\alpha=5 \%)$, yang artinya terima $\mathrm{H}_{0}$ tolak $\mathrm{H}_{\mathrm{a}}$. Jadi harga kopi arabika roasting specialty tidak signifikan terhadap permintaan kopi arabika roasting. Sehingga dapat disimpulkan bahwa harga kopi arabika roasting specialty tidak berpengaruh nyata terhadap permintaan kopi arabika roasting.

\section{Harga Greenbean Arabika Specialty $\left(\mathrm{X}_{2 \mathrm{a}}\right)$}

Berdasarkan hasil analisis regresi linear Tabel 9 dapat dijelaskan yaitu setiap peningkatan harga greenbean arabika specialty sebesar Rp.1,-/Kg akan menyebabkan jumlah permintaan kopi arabika roasting meningkat sebesar $0,853 \mathrm{Kg}$ dengan asumsi variabel lain tetap. Berdasarkan hasil uji-t statistik, hasil analisis harga greenbean arabika specialty yang didapatkan $t_{\text {hitung }}$ sebesar 7,081, dengan tingkat signifikansi sebesar 0,000 , maka nilai $t_{\text {hitung }}$ $7,081>t_{\text {tabel }} 2,570$ dengan tingkat kepercayaan 95\% dan tingkat signifikansi $0,05(\alpha=5 \%)$, yang artinya terima $\mathrm{Ha}$ tolak $\mathrm{H}_{0}$. Harga greenbean arabika specialty signifikan terhadap permintaan kopi arabika roasting. Sehingga dapat disimpulkan bahwa harga greenbean arabika specialty berpengaruh nyata terhadap permintaan kopi arabika roasting.

\section{Harga Kopi Robusta $\left(\mathbf{X}_{3}\right)$}

Berdasarkan hasil analisis regresi linear Tabel 9 dapat dijelaskan yaitu setiap peningkatan harga kopi robusta sebesar Rp.1,-/Kg akan menyebabkan jumlah permintaan kopi arabika roasting meningkat sebesar $0,006 \mathrm{Kg}$ dengan asumsi variabel lain tetap. Berdasarkan hasil uji-t statistik, hasil analisis harga kopi robusta yang didapatkan $t_{\text {hitung }}$ Sebesar 0,150 dengan tingkat signifikansi sebesar 0,884, maka nilai $\mathrm{t}_{\text {hitung }} 0,150<\mathrm{t}_{\text {tabel }} 2,570$ dengan tingkat kepercayaan 95\% dan tingkat signifikansi $0,05(\alpha=5 \%)$, yang artinya terima $\mathrm{H}_{0}$ tolak $\mathrm{H}_{\mathrm{a}}$. Harga kopi robusta tidak signifikan terhadap permintaan kopi arabika roasting. Sehingga dapat disimpulkan bahwa harga kopi robusta tidak berpengaruh nyata terhadap permintaan kopi arabika roasting.

\section{Promosi $\left(\mathbf{X}_{4}\right)$}

Berdasarkan hasil analisis regresi linear Tabel 9 dapat dijelaskan yaitu hasil uji regresi didapatkan nilai $t_{\text {hitung }}$ sebesar 1,843 dengan tingkat signifikansi maka nilai $t_{\text {hitung }} 1,843<\mathrm{t}_{\text {tabel }}$ 2,570 dan dengan tingkat signifikansi sebesar 0,095 > 0,05 yang berarti terima $\mathrm{H}_{0}$ tolak $\mathrm{H}_{\mathrm{a}}$. Maka tidak ada pengaruh yang signifikan antara promosi dengan permintaan kopi arabika roasting.

\section{Pengujian Hipotesis II}

Pada hipotesis kedua faktor-faktor yang mempengaruhi permintaan kopi arabika roasting ada 4 variabel independen yaitu harga kopi arabika roasting premium $\left(\mathrm{X}_{1 \mathrm{~b}}\right)$, harga greenbean arabika premium $\left(\mathrm{X}_{2 \mathrm{~b}}\right)$, harga kopi robusta $\left(\mathrm{X}_{3}\right)$, promosi $\left(\mathrm{X}_{4}\right)$. Dan variabel permintaan kopi arabika roasting $(\mathrm{Y})$. hasil estimasi koefisien regresi yang diperoleh dapat dilihat pada Tabel 5. 
Tabel 5. Hasil Analisis Regresi Linear Hipotesis II

\begin{tabular}{|c|c|c|c|c|c|c|c|}
\hline \multirow[t]{2}{*}{ Model } & \multicolumn{2}{|c|}{$\begin{array}{c}\text { Unstandardized } \\
\text { Coefficients }\end{array}$} & \multirow{2}{*}{$\begin{array}{c}\text { Standardized } \\
\text { Coefficients }\end{array}$} & \multirow[t]{2}{*}{$\mathrm{T}$} & \multirow[t]{2}{*}{ Sig. } & \multicolumn{2}{|c|}{$\begin{array}{c}\text { Collinearity } \\
\text { Statistics }\end{array}$} \\
\hline & $\mathrm{B}$ & Std. Error & & & & Tolerance & VIF \\
\hline (Constant) & $-5,814$ & 1,753 & & $-3,317$ & ,008 & & \\
\hline $\mathrm{X} 1 \mathrm{~b}$ & ,052 & , 103 & ,063 &, 502 & ,626 & ,823 & 1,214 \\
\hline $\mathrm{X} 2 \mathrm{~b}$ & ,707 &, 127 & ,876 & 5,567 &, 000 & ,522 & 1,917 \\
\hline X3 & ,023 &, 075 &, 049 & ,302 & ,769 & ,498 & 2,007 \\
\hline $\mathrm{X} 4$ & ,002 & ,039 & ,004 &, 039 & ,970 & ,975 & 1,026 \\
\hline
\end{tabular}

Sumber : Data Primer (di olah), 2016

Pada tabel diatas dapat diambil persamaan regresi linier berganda sebagai berikut:

$$
Y=5,814+0,052 X_{1 b}+0,707 X_{2 b}+0,023 X_{3}+0,002 X_{4}
$$

\section{HargaKopi Arabika Roasting Premium $\left(\mathrm{X}_{1 \mathrm{~b}}\right)$}

Berdasarkan hasil analisis regresi linear Tabel 10 dapat dijelaskan yaitu setiap peningkatan harga kopi arabika roasting premium sebesar $\mathrm{Rp} .1,-/ \mathrm{Kg}$ akan menyebabkan jumlah permintaan kopi arabika roasting meningkat sebesar $0,052 \mathrm{Kg}$ dengan asumsi variabel lain tetap. Berdasarkan hasil uji-t statistik, hasil analisis harga kopi arabika roasting premium yang diperoleh dengan $t_{\text {hitung }}$ sebesar 0,502, maka nilai $t_{\text {hitung }}<t_{\text {tabel }}$ yaitu 0,502 < 2,570. Atau dapat dilihat juga berdasarkan tingkat signifikan sebesar 0,502 >0,05 yang yang artinya terima $\mathrm{H}_{0}$ dan tolak $\mathrm{H}_{\mathrm{a}}$, Jadi harga kopi arabika roasting premium tidak signifikan terhadap permintaan kopi arabika roasting. Sehingga dapat disimpulkan bahwa harga kopi arabika roasting premium tidak berpengaruh nyata terhadap permintaan kopi arabika roasting.

\section{Harga Greenbean Arabika Premium $\left(\mathbf{X}_{2 b}\right)$}

Berdasarkan hasil analisis regresi linear Tabel 10 dapat dijelaskan yaitu setiap peningkatan harga kopi greenbean arabika premium sebesar Rp.1,-/Kg akan menyebabkan jumlah permintaan kopi arabika roasting meningkat sebesar $0,707 \mathrm{Kg}$ dengan asumsi variabel lain tetap. Berdasarkan hasil uji-t statistik, hasil analisis harga greanbean arabika premium yang didapatkan $t_{\text {hitung }}$ sebesar 5,567 dan $t_{\text {tabel }} 2,570$ sehingga $t_{\text {hitung }}>t_{\text {tabel }}$ yang artinya $\mathrm{H}_{\mathrm{a}}$ diterima $\mathrm{H}_{0}$ ditolak. Sehingga hal tersebut berpengaruh nyata karena memiliki nilai signifikansi $(u j i \mathrm{t})=0,000$ terhadap jumlah permintaan kopi arabika roasting.

\section{Harga Kopi Robusta $\left(\mathbf{X}_{3}\right)$}

Berdasarkan hasil analisis regresi linear Tabel 10 dapat dijelaskan yaitu setiap peningkatan harga kopi robusta sebesar Rp.1,-/Kg akan menyebabkan jumlah permintaan kopi arabika roasting meningkat sebesar $0,023 \mathrm{Kg}$ dengan asumsi variabel lain tetap. Dan berdasarkan hasil uji-t statistik, hasil analisis harga kopi robusta yang didapatkan $t_{\text {hitung }}$ sebesar 0,302 dengan tingkat signifikansi sebesar 0,769 maka nilai $\mathrm{t}_{\text {hitung }} 0,302<\mathrm{t}_{\text {tabel }} 2,570$ dengan tingkat kepercayaan 95\% dan tingkat signifikansi $0,05(\alpha=5 \%)$, yang artinya terima $\mathrm{H}_{0}$ dan tolak $\mathrm{H}_{\mathrm{a}}$. Jadi harga kopi robusta tidak signifikan terhadap permintaan kopi arabika roasting. Sehingga dapat disimpulkan bahwa harga kopi robusta tidak berpengaruh nyata terhadap permintaan kopi arabika roasting.

\section{Promosi $\left(\mathbf{X}_{4}\right)$}

Berdasarkan hasil analisis regresi linear Tabel 10 dapat dijelaskan yaitu hasil uji regresi didapatkan nilai $t_{\text {hitung }} 0,039<t_{\text {tabel }} 2,570$ dan dengan tingkat signifikansi sebesar 0,970 $>0,05$ 
yang berarti terima $\mathrm{H}_{0}$ dan tolak $\mathrm{H}_{\mathrm{a}}$. Maka tidak ada pengaruh yang signifikan antara promosi dengan permintaan kopi arabika roasting.

\section{Pengujian Hipotesis III}

Pada hipotesis ketiga faktor-faktor yang mempengaruhi kopi arabika roasting ada 4 variabel independen yaitu harga kopi arabika roasting longberry $\left(\mathrm{X}_{1 \mathrm{c}}\right)$, harga greenbean arabika longberry $\left(\mathrm{X}_{2 \mathrm{c}}\right)$, harga kopi robusta $\left(\mathrm{X}_{3}\right)$, promosi $\left(\mathrm{X}_{4}\right)$. Dan variabel permintaan kopi arabika roasting (Y). hasil estimasi koefisien regresi yang diperoleh dapat dilihat pada Tabel 6.

Tabel 6. Hasil Analisis Regresi Linear Hipotesis III

\begin{tabular}{|ll|r|r|r|r|r|r|r|}
\hline \multirow{2}{*}{ Model } & \multicolumn{2}{|c|}{$\begin{array}{c}\text { Unstandardized } \\
\text { Coefficients }\end{array}$} & $\begin{array}{c}\text { Standardized } \\
\text { Coefficients }\end{array}$ & \multirow{2}{*}{$\mathrm{T}$} & \multirow{2}{*}{ Sig. } & \multicolumn{2}{c|}{$\begin{array}{c}\text { Collinearity } \\
\text { Statistics }\end{array}$} \\
\cline { 2 - 4 } \cline { 6 - 8 } & \multicolumn{1}{|c|}{ B } & Std. Error & \multicolumn{1}{c|}{ Beta } & & & Tolerance & VIF \\
\hline 1 & (Constant) & $-5,476$ & 1,083 & & $-5,056$ &, 000 & & \\
X1c &, 024 &, 047 &, 045 &, 498 &, 629 &, 565 & 1,769 \\
X2c &, 703 &, 070 &, 950 & 10,077 &, 000 &, 512 & 1,951 \\
X3 &, 025 &, 049 &, 054 &, 513 &, 619 &, 412 & 2,426 \\
X4 &, 011 &, 028 &, 034 &, 410 &, 690 &, 672 & 1,487 \\
\hline
\end{tabular}

Sumber : Data Primer (di olah), 2016

Pada tabel diatas dapat diambil persamaan regresi linier berganda sebagai berikut:

$$
Y=-5,476+0,024 X_{1 c}+0,703 X_{2 c}+0,025 X_{3}+0,011 X_{4}
$$

\section{HargaKopi Arabika Roasting Longberry $\left(\mathrm{X}_{1 \mathrm{c}}\right)$}

Berdasarkan hasil analisis regresi linear Tabel 14 dapat dijelaskan yaitu setiap peningkatan harga kopi arabika roasting longberry sebesar $\mathrm{Rp} .1,-/ \mathrm{Kg}$ akan menyebabkan jumlah permintaan kopi arabika roasting meningkat sebesar $0,024 \mathrm{Kg}$ dengan asumsi variabel lain tetap. Dan berdasarkan hasil uji-t statistik, hasil analisis harga kopi arabika roasting longberry yang didapatkan $t_{\text {hitung }}$ sebesar 0,498 dengan tingkat signifikansi sebesar 0,629, maka nilai $t_{\text {hitung }} 0,498<\mathrm{t}_{\text {tabel }} 2,570$ dengan tingkat kepercayaan $95 \%$ dan tingkat signifikansi $0,05(\alpha=5 \%)$, yang artinya terima $\mathrm{H}_{0}$ dan tolak $\mathrm{H}_{\mathrm{a}}$.Jadi harga kopi arabika roasting longberry tidak signifikan terhadap permintaan kopi arabika roasting. Sehingga dapat disimpulkan bahwa harga kopi arabika roasting longberry tidak berpengaruh nyata terhadap permintaan kopi arabika roasting.

\section{Harga Greenbean Arabika Longberry $\left(\mathrm{X}_{2 \mathrm{c}}\right)$}

Berdasarkan hasil analisis regresi linear Tabel 14 dapat dijelaskan yaitu setiap peningkatan harga kopi greenbean arabika longberry sebesar Rp.1,-/Kg akan menyebabkan jumlah permintaan kopi arabika roasting meningkat sebesar $0,703 \mathrm{Kg}$ dengan asumsi variabel lain tetap. Dan berdasarkan hasil uji-t statistik, hasil analisis harga greenbean arabika longberry yang didapatkan $t_{\text {hitung }}$ sebesar 10,077 dan $t_{\text {tabel }} 2,570$ yang artinya $\mathrm{H}_{\mathrm{a}}$ diterima $\mathrm{H}_{0}$ ditolak. Sehingga hal tersebut berpengaruh nyata karena memiliki nilai signifikansi (uji $\mathrm{t}$ ) $=$ 0,000 terhadap permintaan kopi arabika roasting.

\section{Harga Kopi Robusta $\left(\mathbf{X}_{3}\right)$}

Berdasarkan hasil analisis regresi linear Tabel 14 dapat dijelaskan yaitu setiap peningkatan harga kopi robusta sebesar Rp.1,-/Kg akan menyebabkan jumlah permintaan kopi arabika roasting meningkat sebesar $0,025 \mathrm{Kg}$ dengan asumsi variabel lain tetap. Dan berdasarkan hasil uji-t statistik, hasil analisis harga kopi robusta yang didapatkan $\mathrm{t}_{\text {hitung }}$ sebesar 0,513 dengan tingkat signifikansi sebesar 0,619 maka nilai $t_{\text {hitung }} 0,513<t_{\text {tabel }} 2,570$ 
dengan tingkat kepercayaan 95\% dan tingkat signifikansi $0,05(\alpha=5 \%)$, yang artinya terima $\mathrm{H}_{0}$ dan tolak $\mathrm{H}_{\mathrm{a}}$. Jadi harga kopi robusta tidak signifikan terhadap permintaan kopi arabika roasting. Sehingga dapat disimpulkan bahwa harga kopi robusta tidak berpengaruh nyata terhadap permintaan kopi arabika roasting.

\section{Promosi $\left(\mathbf{X}_{4}\right)$}

Berdasarkan hasil analisis regresi linear Tabel 12 dapat dijelaskan yaitu hasil uji regresi didapatkan nilai $t_{\text {hitung }} 0,410<t_{\text {tabel }} 2,570$ dan dengan tingkat signifikansi sebesar 0,690 $>0,05$ yang berarti terima $\mathrm{H}_{0}$ dan tolak $\mathrm{H}_{\mathrm{a}}$. Maka tidak ada pengaruh yang signifikan antara promosi dengan permintaan kopi arabika roasting.

\section{KESIMPULAN DAN SARAN}

Dari hasil uraian yang telah di kemukakan yang di peroleh dari hasil penelitian, maka dapat disimpulkan bahwa, hasil estimasi identifikasi masalah I diperoleh nilai R-Squared (R2) sebesar 0,960 artinya variasi yang terjadi pada variabel permintaan kopi arabika roasting (Y), secara simultan dapat dijelaskan oleh variabel-variabel harga kopi arabika roasting specialty (X1a), harga greanbean arabika specialty (X2a), harga kopi robusta (X3), dan promosi (X4), sebesar 96,0 \% dan secara parsial hanya dipengaruhi oleh variabel harga greenbean arabika specialty (X2a). Hasil estimasi identifikasi masalah 2 diperoleh nilai R-Squared (R2) sebesar 0,871 artinya variasi yang terjadi pada variabel permintaan kopi arabika roasting (Y), secara simultan dapat dijelaskan oleh variabel-variabel harga kopi arabika roasting premium (X1b), harga greanbean arabika premium (X2b), harga kopi robusta (X3), dan promosi (X4), sebesar $87,1 \%$ dan secara parsial hanya dipengaruhi oleh variabel harga greanbean arabika premium (X2b). Kemudian hasil estimasi identifikasi masalah 3 diperoleh nilai R-Squared (R2) sebesar 0,954 artinya variasi yang terjadi pada variabel permintaan kopi arabika roasting (Y), secara simultan dapat dijelaskan oleh variabel-variabel harga kopi arabika roasting longberry (X1c), harga greanbean arabika longberry (X2c), harga kopi robusta (X3), dan promosi (X4), sebesar $95,4 \%$ dan secara parsial hanya dipengaruhi oleh variabel harga greanbean arabika longberry (X2c).

Berdasarkan kesimpulan yang telah dipaparkan diatas, maka peneliti memberikan beberapa saran yaitu permintaan kopi arabika roasting di Kecamatan Bandar Kabupaten Bener Meriah, setiap bulannya selalu mengalami peningkatan, oleh karena itu para pengusaha kopi perlu meningkatkan produktivitas dan kualitas kopi yang dihasilkan sehingga dapat bersaing dipasar international (pasar ekspor). Untuk peneliti berikutnya, penelitian kopi arabika roasting masih perlu menggali faktor lain yang lebih nyata pengaruhnya terhadap permintaan kopi arabika roasting.

\section{DAFTAR PUSTAKA}

Badan Pusat Statistik. 2014. Aceh Dalam Angka 2014. BPS. Aceh. Banda Aceh.

Fahmi, M. 2013. Analisis Strategi Pemasaran Kopi Arabika Bergendal Koffie Di Kabupaten Bener Meriah. Unsyiah. Banda Aceh.

Ghozali, I. 2009. Aplikasi Analisis Multivariate Dengan Program SPSS. Semarang: UNDIP. 
Muloto, Sri. 2002. Simposium Kopi 2002 Dengan Tema Mewujudkan Perkopian Nasional Yang Tangguh Melalui Diservikasi Usaha Berwawasan Lingkungan Dalam Pengembangan Industri Kopi Bubuk Skala Kecil Untuk Meningkatkan Nilai Tambah Usaha Kopi Rakyat. Pusat Penelitian Kopi dan Kakao di Indonesia. Denpasar.

Riduwan dan Akdon. 2009. Aplikasi Statistika dan Metode Penelitian untuk Administrasi dan Manajemen. Dewa Ruci. Bandung.

Ridwansyah. 2003. Pengolahan Kopi. http:/www.library.usu.ac.id/download/fp/ tekper-ridwansyah4.pdf. Diakses 19/03/2016.

Singgih, S. 1999. SPSS. PT. Elex Media Komputindo. Jakarta.

Siswoputranto. 1993. Kopi International dan Indonesia. Kanisius. Yogyakarta.

Sugiyono. 2010. Statistik untuk penelitian. Alfabeta. Bandung. 